\title{
Design of Single Phase Cyclo-Converter Using Cascaded Multilevel Inverter
}

\author{
Mohan Raj.M.R ${ }^{1,}$ Uma Maheshwari.G ${ }^{2}$ \\ ${ }^{1} P G$ Scholar, Dept. of Electrical and Electronics Engineering Paavai Engineering College, Namakkal, India \\ ${ }^{2}$ Assistant professor, EEE Dept., Paavai Engineering College, Namakkal, India
}

\begin{abstract}
This paper presents a single phase AC/DC/AC converter based on parallel AC/DC and cascaded multi-level DC/AC Converter. For a two-cell AC/DC/AC converter, two units of full-bridges are connected in parallel and two units of full-bridges are connected in cascade. It is proposed that instead of using two separate control loops of DC link voltages at the AC to DC conversion stage, only a single control loop with only one voltage sensor is proposed in this paper when two cells are equally loaded. It is also shown that by controlling only one cell DC link voltage, the other dc link voltage also gets controlled automatically. Use of simple and unipolar ramp comparison control at both the stages leads to fixed switching frequency operation of all the switches along with the improved quality of input current and output voltage as compared to simple PWM control. The simulation result for the proposed topology has been obtained through the MATLAB simulation studies, for a two-cell based parallel cum cascaded AC/DC/AC converter. The experimental verification of the proposed topology and control strategy has been obtained.

Index Terms: AC/DC converter, DC/AC converter, AC/DC/AC Converter, Parallel Converter, Unipolar PWM.
\end{abstract}

\section{Introduction}

High power converters employed in industrial and power system applications employ distribution of power among multiple power semiconductor devices. Advancements in the special topologies of power converters give additional benefits of high reliability, redundancy and better out power quality. Concern of power quality in power systems has gained considerable attention in past decade. Thus these special topologies of power-electronic converters are increasingly used in power conditioning, power filtering, electrical drives, distributed generation applications and development of electric drive trains for large vehicles.

There are many converter topologies that come under the two stages of the AC/DC/AC converter. A single phase to three-phase drive system using two parallel single phase rectifiers are used in [1]-[2]. In order to resolve the problem of circulating currents among the cells different converter topologies have been proposed in [3]-[8]. In all these topologies the THD at the input AC side is reduced considerably but the THD at the output side still remain high. Transformer less back-to-back connected topology used in [5] reduces the cost as well as THD in both input current and output voltage but this additionally increases circulating current. For reducing the THD at output AC voltage a multilevel converter with series connected cells is described in [6]. The converter has reduced harmonics in the output voltage as well as in the input current and has high efficiency but uses separate control loops for each cells of the converter at the AC to DC conversion stage.

Grid interface or utility supplied power conversion mainly involves either AC to DC, DC to AC or combination of both the converters. An AC to DC to AC converter or AC/DC/AC system interfaces two AC subsystems using two stage power conversions that is from AC to DC and then DC to AC. Such AC/DC/AC converters consist of two back-to back AC/DC converters which are interfaced through their DC sides. The advantages of two stage power conversion are simple control, low total harmonic distortions, improved power factor, reduced number of switches, variable frequency output, decoupling of different AC signals, etc. The two main high power converter topologies used in AC/DC and DC/AC converters are parallel converter and multilevel converter, respectively. The parallel converter has the advantage of distribution of currents among the number of subunits, whereas the advantage of multilevel converter is the distribution of voltage among number of subunits of the converter.

In this paper advantage of both these converters are utilized by connecting parallel converter topology in the input stage and cascaded multilevel converter in the output stage of the AC/DC/AC converters. It is shown that unipolar PWM is better for AC/DC converter (high ripple frequency in input current) in input side and simple PWM is better for DC/AC converter at output side due to limitation of cascaded full bridge inverter.

\section{Converter Topology}

Fig. 1 shows the proposed AC/DC/AC converter for two cell converter system. One single AC voltage source $\mathrm{v}_{\mathrm{ac}}$ is used for each cell of the converter connected in parallel in the input AC/DC converter stage. Multiple DC outputs of the parallel inverter are cascaded to give one single AC output in the output DC/AC 
converter stage. The combination of above two-stages thus forms a single-phase AC/DC/AC converter. Each cell contains eight switches. In the first cell, the switches $S_{11}, S_{12}, S_{13}, S_{14}$ and capacitor $C_{1}$ are used to develop AC/DC voltage converter and switches $S_{15}, S_{16}, S_{17}$ and $S_{18}$ are used for full bridge inverter. Similarly, the switches $S_{21}, S_{22}, S_{23}, S_{24}, S_{25}, S_{26}, S_{27}$ and $S_{28}$ are used in the second cell.

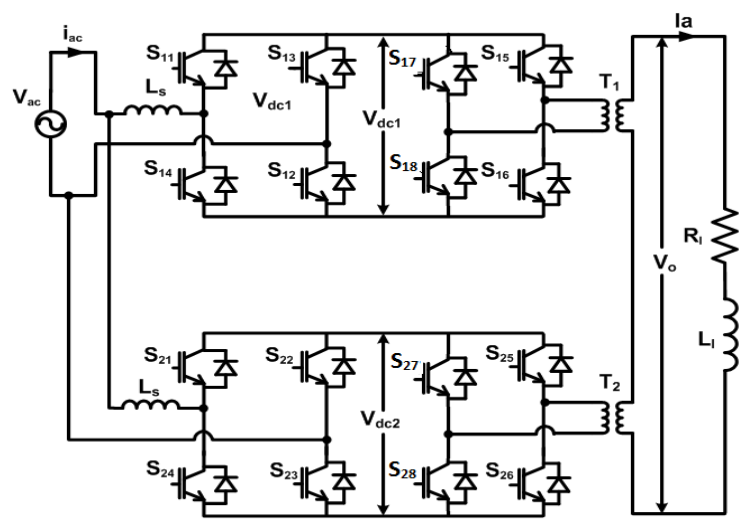

Fig.1. AC/DC/AC converter based on parallel AC/DC converter and cascaded multilevel inverter

The voltages $\mathrm{V}_{\mathrm{dc} 1}$ and $\mathrm{V}_{\mathrm{dc} 2}$ represent the DC link voltages of the two cells. The full bridge inverters of two cells are connected in cascade through an AC load. The AC load is considered linear consisting of resistance $R_{1}$ and inductance $L_{l}$. The isolated DC of each of the AC/DC converter stage feeds the full-bridge cells of the cascaded two-level inverter to generate AC output. The output voltage of the inverter is the sum of full-bridge inverter voltages which are in series at any instant. The $v_{\mathrm{o}}$ and $\mathrm{i}_{\mathrm{a}}$ represents the inverter output voltage and current.

\section{Control Of Ac/Dc/Ac Converter}

In this paper ramp comparison current control method is used in AC/DC converter and DC/AC inverter side to obtain the fixed switching frequency operation of the switches as shown in Fig.1.

In this control, the error which is the difference between the reference current $i_{\text {ref }}$ and the actual input current $i_{\text {act }}$ is compared with the fixed switching frequency triangular carrier given by $v_{\text {tri }}$ having frequency $f_{\text {tri }}$ to get the constant switching frequency switching signals. In this control method the error $e$ is proportional to the amplitude of the carrier. However there is minimum amplitude of the carrier below which the switches will not operate at the fixed carrier switching frequency, rather it enters into the multiple crossings and leads to nonuniform switching operation. To determine this minimum amplitude, the criteria of slope should be satisfied. for the AC/DC converter consisting of $\mathrm{AC}$ source with inductance $\mathrm{L}_{\mathrm{s}}$ and $\mathrm{DC}$ link voltage referred towards DC side $\mathrm{V}_{\mathrm{dc}}$ is considered. The minimum amplitude of the carrier for fixed switching frequency operation can be obtained as

$$
V \text { tri } \min =\frac{1}{4 \text { ftri }}\left[\left(\frac{\text { diref }}{d t}\right)+\frac{\text { vdc }}{\text { Ls }}\right]
$$

Equation (1) shows the minimum carrier amplitude for fixed switching frequency for general pulse width modulation. If the amplitude of the triangular carrier $\mathrm{V}_{\text {tri }}$ is chosen according to (1) above, the average switching frequency of the power switches shown in Fig. 1 becomes constant and equal to the carrier frequency.

\subsection{Control of AC/DC converter unit with simple PWM}

For input stage, the principle of boost rectifier along with simple two-level bipolar PWM is used. A control loop is used to convert AC into DC with unity power factor at input AC side as shown in Fig. 2.

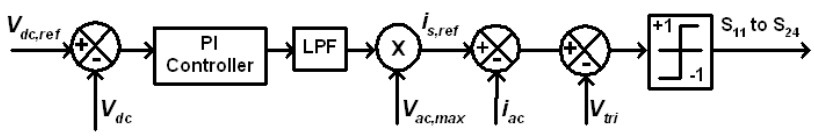

Fig. 2. Control block of rectifier unit with simple PWM.

In this method, the DC link voltages of one cell, i.e. $\mathrm{V}_{\mathrm{dc} 1}$ or $\mathrm{V}_{\mathrm{dc} 2}$, and the input currents of the ac source, $\mathrm{i}_{\mathrm{ac}}$ are sensed and fed-back to generate switching signals for the full bridge switches of two cells to track the common reference $i_{\text {sref }}$ and control the DC link voltages of both the cells to the reference $V_{\text {dcref }}$. A PI controller is 
used to control the DC link voltage and the ramp comparison current controller is used to track the reference current as shown in Fig. 2. The reference current is generated by multiplying the sinusoidal template of same frequency as that of the AC supply voltage. The error of the current is then compared with the triangular carrier to generate the switching signals. The same switching signal is given to both the rectifiers of the two cells.

\subsection{Control of DC/AC inverter unit with simple PWM}

For output stage a simple PWM for current control is used for the cascaded full bridge inverter as shown in the Fig. 3.

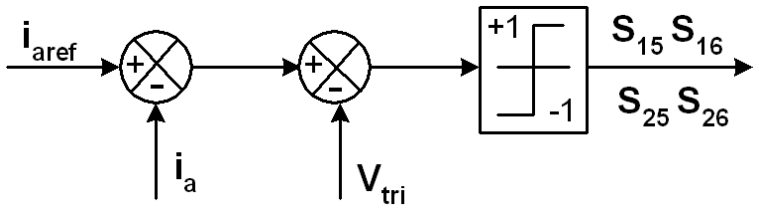

Fig. 3. Control Block of inverter unit

In this the reference current is compared with the actual current to generate error and this error is then compared with a triangular carrier to generate switching signal for the inverter switches. The same control signal is given to both upper and lower full-bridges of the cells.

\subsection{Control of AC/DC/AC converter by Unipolar PWM}

\subsubsection{Unipolar PWM Control of AC/DC Converter}

In this method for input stage boost rectifier along with the unipolar phase shifted multicarrier modulation is proposed for control of the multiple DC link voltages and input current wave-shaping and power factor improvement with reduced current total harmonic distortion. Fig. 4 shows the unipolar PWM control block diagram of the full bridge rectifier to control the DC link voltage at unity power factor. Voltage control loop and reference current generation is same as in the simple PWM. In unipolar PWM, there are two triangular carriers. The first one has the phase of $0^{\circ}$ and other has phase of $180^{\circ}$. The switching signals are generated as shown in the Fig. 4.

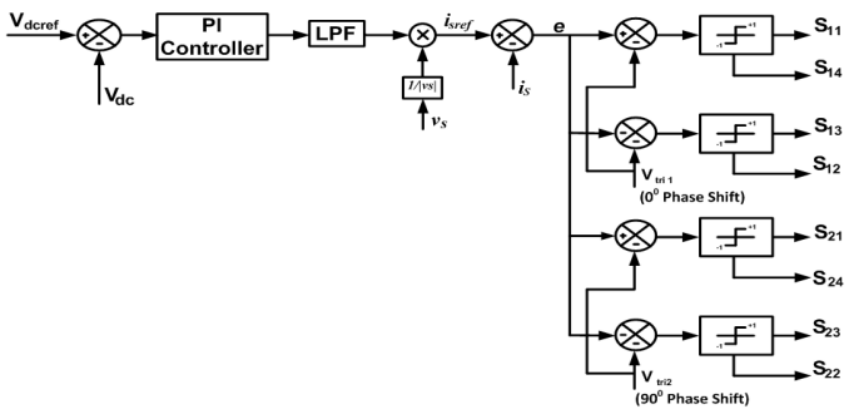

Fig. 4. Control block of rectifier unit with unipolar modulation.

Similarly for carrier phase-shifted unipolar PWM (1) is modified as (2), effective carrier frequency is four times as in simple PWM. Therefore the (2) is modified for unipolar modulation as follows.

$$
V \text { tri } \min =\frac{1}{4 * 4 f t r i ́}\left[\left(\frac{\text { diref }}{d t}\right)+\frac{\text { Vdc }}{L s}\right]
$$

\subsubsection{Control of DC/AC inverter unit with Unipolar PWM}

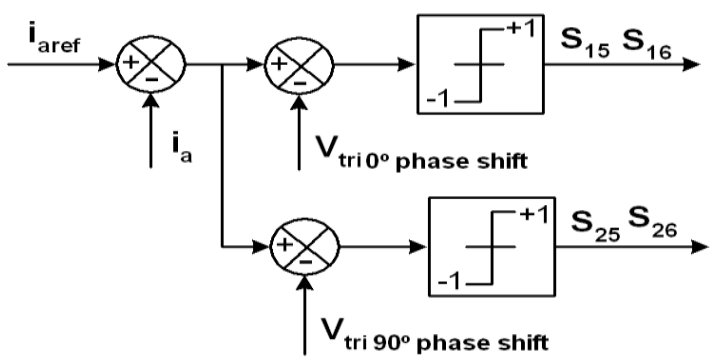

Fig.5. Control Block of inverter unit. 
For output stage, the principle of triangular carrier comparison method of current control with unipolar phase shifted multicarrier modulation is proposed for better current tracking and improved output voltage total harmonic distortion. The unipolar pulse width modulation of full bridge inverter is shown in the Fig. 5. In this two triangular carriers, one with $0^{\circ}$ phase and another with $180^{\circ}$ is used.

Like simple PWM control of inverter, the error is compared with the two triangular carriers to generate the gating signals. For upper cell full bridge inverter, gating signals are generated for the switches $S_{15}$ and $S_{16}$ shown in Fig. 1. The same error signal is again compared with $180^{\circ}$ phase shifted triangular carrier to generate the switching signal for the lower cell full bridge inverter switches $S_{25}$ and $S_{26}$ as shown in Fig. 1.

\section{Simulation Results}

In this section, simulation is performed for the proposed two-cell AC/DC/AC converter in MATLABSimulink. The parameters considered for the power circuit of the converter are given in Table I.

TABLE 1

PARAMETERS FOR SIMULATION

\begin{tabular}{|l|l|}
\hline Parameters & Numerical value \\
\hline Input AC supply and inductance & $120 \mathrm{~V}, 1 \mathrm{mH}$ \\
\hline DC capacitor & $2 \mathrm{mF}$ \\
\hline Transformer & $600 / 600 \mathrm{~V}, 5 \mathrm{KVA}$ \\
\hline Load resistance and inductance & $100 \Omega, 1 \mathrm{mH}$ \\
\hline DC link voltage & $200 \mathrm{~V}$ \\
\hline Switching frequency & $2.5 \mathrm{KHz}$ \\
\hline $\mathrm{I}_{\mathrm{ref}}$ at AC side & $12 \mathrm{~A}($ peak $)$ \\
\hline
\end{tabular}

The other parameters used for simulation are proportional controller gain, $\mathrm{K}_{\mathrm{P}}=0.015$; integral controller gain, $K_{i}=9$. It has describe the output of cascaded multilevel inverter voltage and current with the 5 level inverter

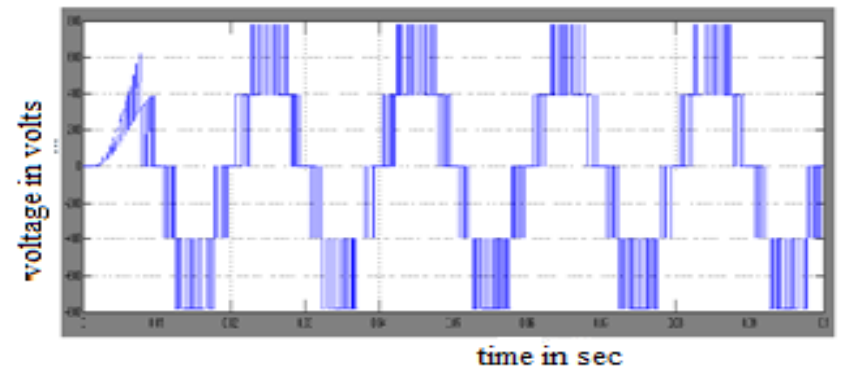

Fig.6 output voltage of cascaded multilevel inverter

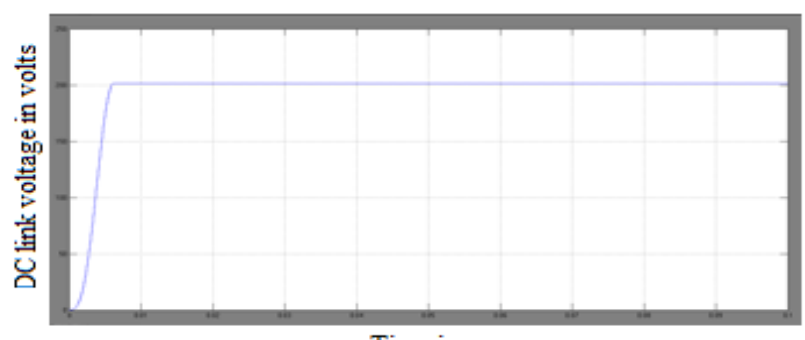

Time in sec

Fig.7 DC link voltage from the rectifier unit

The output voltage of cascaded multilevel inverter and the DC link voltage obtained from the rectifier terminal are shown in figure 6 and 7.

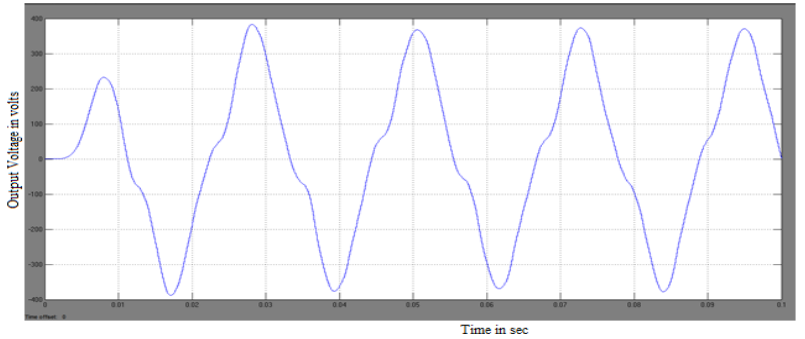

Fig.8. output voltage of converter 


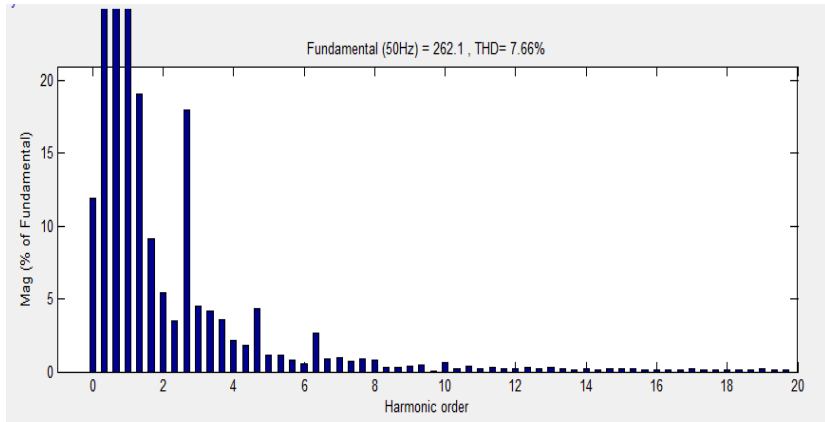

Fig.9. FFT plot for output voltage of AC/DC/AC converter

Fig 8 and 9 shows the output voltage of converter and its FFT plot. The total harmonic distortion (THD) of output ac voltage in AC/DC/AC converter is 7.66\%. The unipolar PWM control has better quality and low THD as compared simple PWM control as the switching components shifts to the frequency at $4 \mathrm{f}_{\text {tri }}$ due the property of unipolar phase-shifted multi-carrier PWM. The converter has reduced harmonics in the output voltage as well as in the input current and has high efficiency.

\section{Conclusions}

In this paper single loop control with unipolar PSPWM is implemented to control the DC link voltages of two cells of parallel connected AC/DC/AC converter. It is shown that the control method achieves less THD along with the improved quality of the input current of the AC/DC converter. It is also verified that the ripple frequency in input current is four times of the carrier frequency in unipolar PWM due harmonics cancellation. The power rating of each cell reduces to half for two cells AC/DC/AC converter in comparison if one cell AC/DC/AC converter is used.

\section{References}

[1]. J.Choi and F.C.Lee, "Control of Circulating Current in Two Parallel Three Phase Boost Rectifiers," IEEE Trans. Power Electron, vol. 17, no.5.2002.

[2]. C.B.Jacobina, N.Rocha, and E.L.Fabrico, "Single Phase to Three PhaseDrive System Using Two Parallel Single Phase Rectifiers," IEEE Trans. Power Electron., vol. 25, no.5.May, 2010.

[3]. C.R.Balamurugan "Investigations on Three Phase Five Level Flying Capacitor Multilevel Inverter", IJET Explore, Volume 2 No. 7 , July, 2012.

[4]. J.S.Larsen, K.Jespersen, M.R.Pedersen, F.Blaabjerg and J. K.Pedersen, "Control of a complete digital-based component-minimized single-phase to three-phase AC/DC/AC converter," In Proc. IEEE IECON'98, pp.618 - 625 Aug. /Sept. 1998.

[5] B.R.Lin, "Analysis and implementation of a three-level PWM rectifier/inverter", IEEE Trans. Aerospace and Electronics System, vol. 36, no. 3, part: 1, pp. 948-956, July 2000

[6]. Aquila.A.D, Liserre.M and Monopoli.V.G, "Design of a back-to back multilevel induction motor drive for traction systems," In Proc.IEEE PESC’03, pp. 1764 - 1769, June 2003.

[7]. $\quad$ B.R.Silvax, C.Silva and P.Lezana, "High-voltage multilevel converter with regeneration capability," in Proc. IEEE PESC'99, pp. 1077 - 1082, June/July 1999.

[8]. S.Lai and F.Peng, "Multilevel converters-A new breed of power converters,"IEEE Trans. Ind. Applications, vol.32, pp-509-517, May/June 1996

[9]. J.S.Lai, and F.Z.Peng, "Multilevel inverters: A survey of topologies, control, and applications", IEEE Trans. on Ind. Electron., vol.49, pp.724-738, Aug. 2002

[10]. A.Pandey, B.Singh, and D.P.Kothari, “A review of multilevel power converters” IEEE IE(I) Journal. EL, Vol.86, March 2006

[11]. J.I.Leon, S.Kouro, R.Portillo and A.M.Maria, "The Age of Multilevel Converters Arrives" IEEE Industrial Electronics Magazine, June 2008.

[12]. Power electronics handbook: devices, circuits, and applications a book by M. H. Rashid. 